\title{
Sodium Valproate in Treatment of Epilepsy
}

\author{
PETER M. JEAVONS, JEAN E. CLARK
}

British Medical fournal, 1974, 2, 584-586

\begin{abstract}
Summary
Sodium valproate has a simple chemical structure unlike other anticonvulsants. It has been given to 63 patients with various types of epilepsy whose attacks were frequent and of whom 40 had failed to respond to other anticonvulsants. Fits stopped completely in 27 patients $(43 \%)$ and $14(22 \%)$ showed a reduction of attacks by more than $50 \%$. The best results were in patients with absences (typical and atypical) associated with spike and wave discharges on the electroencephalogram. Myoclonic epilepsies responded well and improvement occurred with tonic-clonic seizures and focal motor fits. There was little or no improvement in temporal lobe epilepsy. Sodium valproate given alone did not cause unwanted effects but it potentiated many other anticonvulsants. An unusual side effect was temporary hair loss. $A$ number of patients became more alert, school performances improved, and the management of subnormal patients became easier.
\end{abstract}

\section{Introduction}

The anticonvulsant effects of sodium dipropylacetate (sodium valproate) were first reported in France (Meunier et al., 1963). There have been numerous reports in the European literature on its clinical effects, the most recent being those of Völzke and Doose (1973) and Kugler et al. (1973). Unlike other anticonvulsants sodium valproate has a simple chemical formula (see fig. 1). It is excreted mainly in the urine and has an average half life of 10 hours. It has been suggested that it acts by inhibiting $\gamma$-aminobutyric acid transaminase (Godin et al., 1969; Simler et al., 1973).

We report here the effects of sodium valproate in patients with epilepsy.

\section{Patients and Methods}

Altogether 63 patients were studied-34 female and 29 male. Their ages ranged from 10 months to 43 years, most being between 6 and 20 years. In order to obtain early results patients were admitted to the trial only if they had more than four fits a month. A total of 43 were having frequent fits -8 had hourly attacks, 20 had daily fits, 5 had many fits a week, and 10 had an average of 10 fits a month. Most patients suffered from severe epilepsy of long duration which had failed to respond to therapy with many anticonvulsants (table I). Apart from these intractable cases a few were selected because their electroencephalograms (E.E.G.s) showed spike and wave discharges and some because

Dudley Road Hospital, Birmingham B18 7QH

PETER M. JEAVONS, M.R.C.P., F.R.C.PSYCH., Consultant in Electroencephalography

Children's Hospital, Ladywood, Birmingham B16 8ET

JEAN E. CLARK, M.B., D.OBST. R.C.O.G., Assistant Medical Officer

$$
\begin{aligned}
& \mathrm{CH}_{3}-\mathrm{CH}_{2}-\mathrm{CH}_{2} \\
& \mathrm{CH}_{3}-\mathrm{CH}_{2}-\mathrm{CH}_{2} \\
& \text { FIG. } 1 \text {-Sodium valproate. }
\end{aligned}
$$

\begin{tabular}{|c|c|c|c|c|c|}
\hline & & & $\begin{array}{l}\text { No. of } \\
\text { Cases }\end{array}$ & $\begin{array}{c}\text { Average Duration } \\
\text { (Years) }\end{array}$ & $\begin{array}{l}\text { Average No. } \\
\text { of Drugs Tried }\end{array}$ \\
\hline $\begin{array}{l}\text { Absences with } \\
\text { spike and wave } \\
\text { Myoclonic astatic } \\
\text { Temporal lobe } \\
\text { Focal motor }\end{array}$ & $\begin{array}{l}\because \\
\because \\
\cdots\end{array}$ & $\begin{array}{l}\because \\
\because \\
\cdots\end{array}$ & $\begin{array}{l}12 * \\
11 \\
10 \\
4\end{array}$ & $\begin{array}{r}11 \\
8 \\
10 \\
7\end{array}$ & $\begin{array}{l}5 \\
6 \\
6 \\
6\end{array}$ \\
\hline
\end{tabular}

TABLE I-Type and Duration of Epilepsy and Number of Drugs Tried

* Longstanding cases only.

of their abnormal E.E.G. responses to intermittent photic stimulation (I.P.S.)

Seventeen patients had absences, often atypical with automatisms but all with spike and wave discharges on the E.E.G. One patient had an 11-year history of absence status every two months.

Five patients had myoclonic jerks only. Five others had myoclonic jerks, most often in the early morning after waking, and also showed spike and wave discharges on I.P.S. Eleven patients had myoclonic astatic epilepsy (Lennox syndrome), the most intractable form of childhood epilepsy. Falls, generalized myoclonic jerks, eyelid flutter, and astatic attacks were frequent and many also had tonic-clonic seizures.

There were 10 photosensitive patients; five had fits only when watching television and four had flicker-induced fits as well as "spontaneous" ones. One boy had micropsia only, with spike and wave discharges on I.P.S.

Ten patients had temporal lobe epilepsy and four had focal motor fits.

One patient had tonic-clonic fits only, but 18 patients with other types of fit also had tonic-clonic seizures.

The duration of therapy was on average six months, ranging from 4 to 11 months. Eleven patients were receiving no anticonvulsant when admitted to the trial.

The initial dose of sodium valproate, regardless of the patient's age or weight, was one tablet $(200 \mathrm{mg}$ ) twice daily increasing to $600 \mathrm{mg}$ daily after three days. The average daily dose was 1,000 mg (range $600-1,400 \mathrm{mg}$ ). In 31 patients other drugs were reduced and in four cases they were stopped.

Blood was taken for haematological and biochemical examination before and during the trial. Every patient or relative kept a daily record of the fits. Many were already doing so.

The results are based on the recorded number of fits, the objective assessment of relatives, teachers, and clinical observers, the patient's own assessment, and the E.E.G. findings. To assess the effect of the drug in various types of epilepsy some patients are included under several headings. The patients with "television" epilepsy were assessed solely on E.E.G. findings.

The results are divided into seven categories according to the degree of improvement, from complete control of seizures or normalization of the E.E.G. ( $100 \%$ improvement) through improvement better than $80 \%, 50 \%, 30 \%$, or $10 \%$ down to no improvement or worse. 
TABLE II-Response to Treatment with Sodium Valproate of Patients with Epilepsy. Some Patients appear in More than One Category

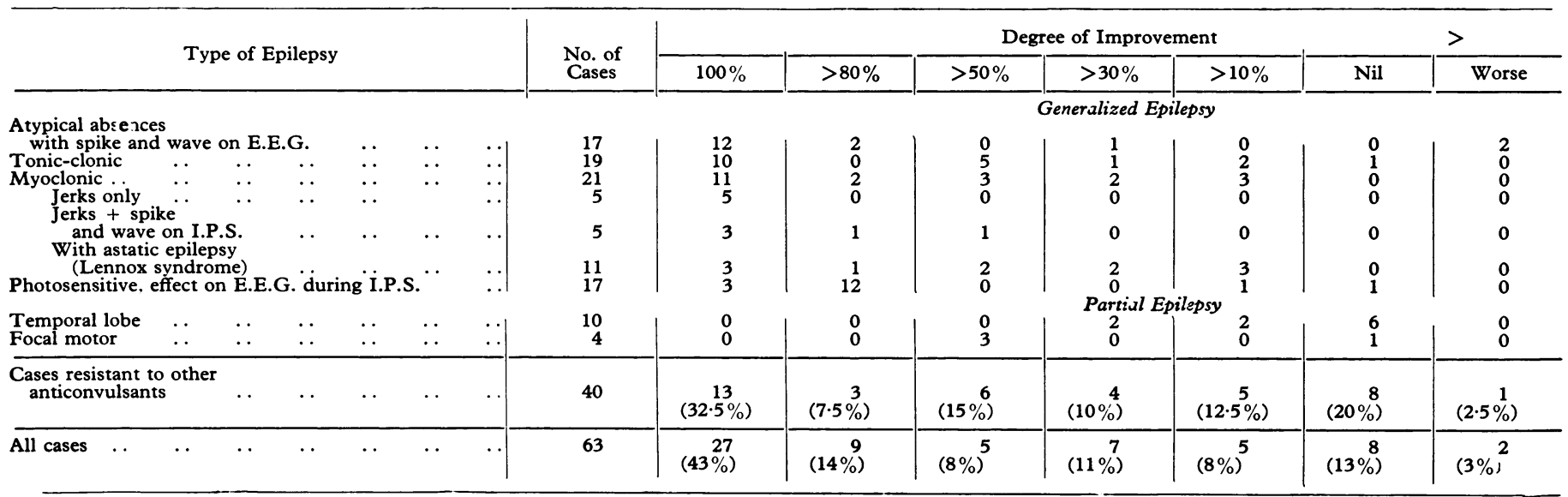

\section{Results}

The best results (table II) were obtained in those patients whose E.E.G.s showed spike and wave discharges and whose attacks consisted of absences with or without automatisms. Of the 17 patients in this category 12 improved $100 \%$ and two improved by more than $80 \%$. Five of these 14 patients had a history of epilepsy for more than 10 years and all had received more than five different anticonvulsants. The patient with an 11-year history of absence status every two months had not responded to a combination of four anticonvulsants. At the time of writing she had not had an attack for eight months and was on only sodium valproate $1,000 \mathrm{mg}$ and phenobarbitone $30 \mathrm{mg}$ daily. Of the 15 patients who showed improvement 11 had previously failed to respond to ethosuximide.

The average time required to achieve control of the attacks was six weeks and the average dose was $1,000 \mathrm{mg}$ daily.

The five patients whose attacks consisted of myoclonic jerks alone (including a boy of 10 months who had jerks and spike and wave discharges every few moments and with every loud noise) were free from fits on sodium valproate by itself. Of the five patients with myoclonic jerks who also showed spike and wave discharges during I.P.S. three were fully controlled and two showed a marked improvement. All showed E.E.G. improvement greater than $80 \%$.

All of the 11 patients with myoclonic astatic epilepsy were retarded. Three were fully controlled, three improved by more than $50 \%$, and the rest showed some improvement. These results are remarkable because this is the most intractable form of epilepsy in childhood; the average duration of the illness was eight years and an average of six drugs had been tried and had failed. The average daily dose of sodium valproate was $1,000 \mathrm{mg}$.

A 12-year-old girl had a nine-year history of myoclonic, astatic, and petit mal attacks and had been treated with nine different anticonvulsants. In May 1973 she had 380 attacks. During the week before starting the trial she had 113 attacks (fig. 2). In the seventh week she had tonsillitis, which was associated with an increase in attacks. The sodium valproate was therefore increased and she became drowsy and ataxic. These symptoms disappeared on withdrawal of carbamazepine. Subsequently she had no fits, was more alert and lively, and was doing better at her special school.

One child of 3 years could not walk alone and two others were afraid to go out alone to play because the frequency of the jerks caused them to fall. All three became not only free from fits but fully mobile and confident,

The results in photosensitive epilepsy are preliminary since this is the subject of a separate trial, but of the five patients with television epilepsy one had a normal E.E.G. and four showed an improvement greater than $80 \%$. Three other patients had no fits and one was $80 \%$ better. The E.E.G. responses tended to be less than the clinical response and may have been partially dependent on dose.

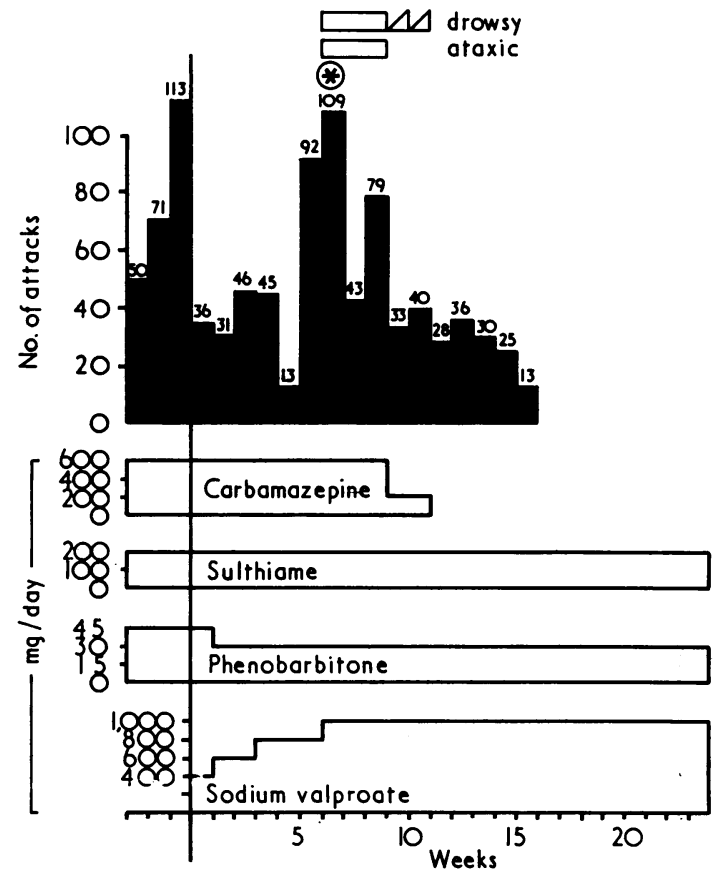

FIG. 2-Clinical course and treatment of girl aged 12. Total of 113 myoclonic astatic attacks occurred in week before receiving sodium valproate. Exacerbation due to tonsillitis in seventh week. Side effects disappeared on withdrawal of carbamazepine. All fits stopped after 16 weeks. Daily sodium valproate $1,000 \mathrm{mg}$.

Tonic-clonic seizures responded well, half of the cases becoming fully controlled.

The effect on temporal lobe epilepsy was poor. Though the patient's tonic-clonic fits diminished and it was possible to reduce some of the other drugs and also induce a feeling of wellbeing in some patients, temporal lobe fits showed no appreciable response despite the fact that this group of patients received a higher average daily dose of sodium valproate $(1,200 \mathrm{mg})$.

The few patients with focal motor seizures showed some inprovement. One boy was admitted with epilepsia partialis continua. He also had absences and frequent tonic-clonic fits which stopped in three days, while the focal fits were reduced to two an hour after six days and had practically diasppeared after 19 days.

\section{OTHER EFFECTS}

Four patients who received sodium valproate alone became 
noticeably brighter and more alert and lively. This welcome response was observed in 17 other patients who were also receiving other anticonvulsants. The change was noted before there had been any reduction in other drugs. A marked increase in appetite occurred in five patients.

Seven retarded patients not only became more alert but showed a pronounced change in mood and became much happier and therefore easier to manage.

\section{UNWANTED EFFECTS}

No unwanted effects were observed in the patients who received sodium valproate alone.

Drowsiness occurred in eight patients, two becoming so drowsy as to be nearly stuporous. In these two cases sodium valproate was stopped; it was later introduced gradually, with reduction of other drugs, without recurrence of stupor. In all cases where drowsiness occurred it rapidly disappeared on reduction of the appropriate anticonvulsant (phenobarbitone one case, nitrazepam four cases, phenytoin one case, ethotoin one case, carbamazepine one case).

Ataxia occurred in four cases and disappeared on reduction or withdrawal of pheneturide, carbamazepine, ethotoin, and phenytoin (one case each). Three patients showed brief gastrointestinal upset, one of them vomiting as a reaction to phenytoin. Behaviour disorders in three children disappeared as soon as primidone was reduced. Overactivity improved with reduction of acetazolamide.

Early in the trial two patients reported some loss of hair, and because of this a letter was sent to all the other patients asking about this symptom. In the subsequent weeks hair loss was reported by six more patients. The eight patients were therefore referred to a dermatologist, who regarded the hair loss as more apparent than real in four. In the other four the loss was slight and not regarded as a contraindication to the use of sodium valproate. The dermatologist felt that with the information available one could not be definite whether the mechanism involved a phase of telogen or anagen effluvium. Subsequently seven other patients reported some hair loss but in only two of these did it appear to be definite, and it thus seems possible that six patients in all showed some hair loss. All these patients had also been receiving phenytoin. No hair loss occurred in patients receiving sodium valproate alone.

Ten patients were withdrawn from the trial. Two had absences because of an increase in attacks (though both had been uncooperative in taking their tablets). A third refused tablets, though she had improved. Seven patients showed no appreciable response after three months, six of them having temporal lobe epilepsy.

\section{E.E.G. FINDINGS}

Four patients had normal E.E.G.s before the trial and were therefore not re-examined. Fifteen patients had had abnormal E.E.G.s, and of these eight had no fits and a normal E.E.G., five became free from fits but still showed some E.E.G. abnormality, and two showed slight improvement.

\section{HAEMATOLOGICAL AND BIOCHEMICAL FINDINGS}

The haematological and biochemical findings gave no reason for concern and there was no evidence of any consistent druginduced changes, most of the values being normal.

\section{Discussion}

When the intractable nature of the epilepsy in 40 of the 63 patients is considered the response of the generalized epilepsies was remarkable and confirms the findings in the European literature. Patients who show spike and wave discharges on their E.E.G.s respond very well and sodium valproate seems to be the most effective drug for typical or atypical absences, since it controls attacks which have not been controlled by ethosuximide. In some cases it must be combined with the latter but in others the ethosuximide can be withdrawn.

The improvement in the myoclonic epilepsies was surprising since most are very difficult to treat.

The response in the partial epilepsies was less and temporal lobe epilepsy responded little if at all. Some response, however, occurred in focal motor epilepsy.

Sodium valproate when used alone is virtually free from unwanted effects other than rare mild gastrointestinal upset, which is temporary and rarely occurs if the drug is introduced gradually and always taken with meals. Nevertheless, side effects are quite common in association with other anticonvulsants and it is important to reduce the other anticonvulsants rather than the sodium valproate if side effects occur. Hair loss is an unusual side effect, having been reported in only a very few cases in Germany (Kugler et al., 1973; Völzke and Doose, 1973). Happily, in the present trial as in Germany it proved temporary.

The time required to achieve improvement was short in the patients with spike and wave discharges and absences but was often several months in other cases, and it was necessary to make frequent adjustments to the medication, management being quite complicated.

We thank Dr. M. A. Cowan for evaluating the problem of hair loss, our colleagues for kindly letting us include their patients in the trial, and Reckitt and Colman for supplying the sodium valproa:e (Epilim). We are very grateful to Dr. Richard Smith and Mr. J. W. King for their help and adice.

\section{References}

Godin, T., Heiner, L., Mark, J., and Mandel, P. (1969). Fournal of Neuro-

chemistry, 16, 869. enschrift, 115, 1103

Meunier, H., Carraz, G., Meunier, Y., and Eymard, M. (1963). Therapie,

18, 435.
Simler, S., Ciesielski, L., Maitre, M., Randrianarisoa, H., and Mandel, P. (1973). Biochemical Pharmacology, 22, 1701.

Völzke, E., and Doose, H. (1973). Epilepsia. Fournal of the International League Against Epilepsy, 14, 185. 